\title{
Characterization of Shear Deformation Based on In-situ Observation of Deformation in Semi-solid Al-Cu Alloys and Water-particle Mixture
}

\author{
Tomoya NAGIRA, ${ }^{1) *}$ Hiroyoshi YOKOTA, ${ }^{10}$ Shugo MORITA, ${ }^{11}$ Hideyuki YASUDA, ${ }^{1)}$ Masato YOSHIYA, ${ }^{11}$ \\ Christopher M. GOURLAY, ${ }^{2)}$ Akira SUGIYAMA, ${ }^{3)}$ Kentarou UESUGI ${ }^{4)}$ and Keiji UMETANI ${ }^{4)}$ \\ 1) Department of Adaptive Machine Systems, Osaka University, 2-1 Yamadaoka Suita, Osaka, 565-0871 Japan. \\ 2) Department of Materials, Imperial College London, London, SW7 2AZ UK. \\ 3) Department of Engineering, Osaka Sangyo University, 3-1-1Nakagaito Daitou, Osaka, 574-8530 Japan. \\ 4) Japan Synchrotron Radiation Research Institute, 1-1-1, Kouto, Sayo-cho, Sayo-gun, Hyogo, 679-5198 Japan.
}

(Received on March 11, 2013; accepted on April 11, 2013; originally published in Tetsu-to-Hagané, Vol. 99, 2013, No. 2, pp. 141-148)

\begin{abstract}
In-situ observation of deformation at the grain scale in semi-solid $\mathrm{Al}-\mathrm{Cu}$ alloys has been carried out using synchrotron X-ray radiography. The deformed microstructure was characterized by the quantitative analysis of solid motion from the image sequences during shear in semi-solid Al-Cu alloys. The influence of solid particle shape on shear deformation was also examined by comparing with in-situ observation of deformation in water-polystyrene particle mixtures where the polystyrene particles are spherical with a diameter of $500 \mu \mathrm{m}$. In both semi-solid Al-Cu alloys and water-particle mixtures, solid particles located close to the shear plane developed an increasing component perpendicular to the shear plane, and a relatively high shear strain rate and decreased solid fraction was localized in a shear domain. The shear band width in semi-solid Al-Cu alloys ( $~ 10$ mean particles diameter) was approximately two times wider than that formed in water-particle mixtures due to the difference in the solid particle shape.
\end{abstract}

KEY WORDS: shear deformation; semi-solid; X-ray imaging; shear band.

\section{Introduction}

It is well known that macrosegregation mainly occurs by fluid flow between dendrite arms and deformation of partially solid alloys during solidification. ${ }^{1)}$ Their driving forces are solidification shrinkage, thermosolutal convection and external forces applied by several casting processes. A large number of researches on the mechanical properties and viscous behavior of semi-solid alloys have been reported for the development of semi-solid processing. ${ }^{2-8)}$ However, there are few researches on the mechanisms of macrosegregation formation caused by deformation in semi-solid alloys. ${ }^{9,10)}$

Segregation bands containing macrosegregation and porosity are often formed in high pressure die casting and centrifugal casting. ${ }^{9-11)}$ This is due to significant stresses acting on semi-solid microstructures. Gourlay et al. ${ }^{9,10)}$ reported that semi-solid metallic alloys show the characteristics of saturated compacted granular materials such as dilatancy, which leads to volume expansion in response to shear. The deformation of semi-solid alloys causes strain localization into a shear band of increased liquid fraction, resulting in a segregation band after solidification. However, the evolution of

* Corresponding author: E-mail: nagira@ams.eng.osaka-u.ac.jp DOI: http://dx.doi.org/10.2355/isijinternational.53.1195 segregation bands is not fully understood. During deformation, solid-liquid and solid-solid interactions lead to various solid and liquid motions such as displacement/rotation of solid particles, impingement between solid particles and liquid flow. As a result, the rheology of semi-solid alloys shows various mechanical phenomena including agglomeration/ disagglomeration, ${ }^{2,3}$ ) deformation of the individual solid particles $^{2,3)}$ and dilatancy during rearrangement of solid particles. ${ }^{9}{ }^{10)}$ These phenomena are influenced by the liquid viscosity, the shear rate and microstructural features including the solid fraction, solid particle size and solid particle shape. It is necessary to study how each phenomenon influences deformation behavior to form a shear band. The most direct approach to understanding microstructural evolution is to observe deformation in-situ at the grain scale.

In-situ observation of solidification behavior in various alloys has been extensively carried out using X-ray imaging at synchrotron radiation facilities. ${ }^{12-21)}$ Recently a similar technique has been applied to in-situ observation of shear deformation in semi-solid $\mathrm{Al}-\mathrm{Cu}$ and $\mathrm{Fe}-\mathrm{C}$ alloys. ${ }^{22-24)}$ The time-resolved sequence of images showed impingement between solid particles and the translation and rotation of solid particles about their contacts in response to shear at the grain scale. Direct evidence for shear-induced dilation caused by the rearrangement of solid particles during shear was presented. 
This paper characterizes the deformed microstructure in semi-solid alloys by the quantitative analysis of solid motion from image sequences obtained by in-situ observation experiments in semi-solid $\mathrm{Al}-\mathrm{Cu}$ alloys. A solid velocity, a shear strain rate and a divergence of solid velocity, which corresponds to a change in solid fraction, were evaluated during shear. The technique for in-situ observation using X-ray imaging directly allows us to examine the microstructural evolution in metallic alloys. It is, however, difficult to precisely control experimental conditions including the solid fraction, grain size and solid particle shape, which can influence deformation behaviors. In this paper, in-situ observation of deformation in water-polystyrene particle mixtures, ${ }^{25)}$ where the polystyrene particles are spherical was also carried out to examine the influence of solid particle shape on deformation behaviors.

\section{Experimental Procedures}

\subsection{Preparation of Semi-solid Al-Cu Alloys and Setup of In-situ Observation}

The ingot with a composition of $\mathrm{Al}-15 \mathrm{Cu}-0.5 \mathrm{Ti}-0.25 \mathrm{~B}$ (mass $\%$ ) was produced by arc-melting. The semi-solid specimen with the globular morphology was produced by partially remelting the fine equiaxed microstructure and isothermally holding for $\sim 40 \mathrm{~min}$. A schematic of the direct shear cell for semi-solid alloys is shown in Fig. 1. The sample with dimensions of $10 \times 10 \mathrm{~mm}$ with $200 \mu \mathrm{m}$ thickness was placed in the mold which consists of an $\mathrm{Al}_{2} \mathrm{O}_{3}$ plate with a thickness of $200 \mu \mathrm{m}$. The mold and $\mathrm{Al}_{2} \mathrm{O}_{3}$ window plates were retained by $\mathrm{BN}$ plates. Isothermal direct shear was applied by a stepping motor that pushed the $\mathrm{Al}_{2} \mathrm{O}_{3}$ push plate with a thickness of $150 \mu \mathrm{m}$ upwards. The $\mathrm{Al}_{2} \mathrm{O}_{3}$ push plate displacement rate was $30 \mu \mathrm{m} / \mathrm{s}$.

Experiments were carried out at beamline BL20B2 of the SPring-8 synchrotron facility, Hyogo, Japan. An X-ray direct-sensing pickup tube SATICON was used as an image detector. $^{26)}$ The X-ray energy was set to be $15 \mathrm{keV}$ to obtain sufficient solid-liquid contrast. The observation area was $5.2 \times 5.2 \mathrm{~mm}$ and the pixel size was $5.1 \mu \mathrm{m} \times 5.1 \mu \mathrm{m}$. The detector acquired eight frames per second.

\subsection{Preparation of Water-particle Mixtures and Setup for In-situ Observation}

Spherical polystyrene particles with a diameter of $500 \pm 10$ $\mu \mathrm{m}(25.1 \mu \mathrm{m}$ standard deviation) were chosen as a solid particle. The particles were dispersed into an aqueous solution of $\mathrm{NaCl}$. The concentration of $\mathrm{NaCl}$ was controlled to equalize the density $\left(1.05 \mathrm{~g} / \mathrm{cm}^{3}\right)$ between polystyrene particles and liquid. A detergent was added in small amounts to the liquid-particle mixtures to prevent agglomeration of the polystyrene particles. A schematic of the direct shear cell for water-particle mixtures is shown in Fig. 2. The water-particle mixtures were put into the mold which consists of teflon plates with dimensions of $10 \times 10 \mathrm{~mm}$ with $800 \mu \mathrm{m}$ thickness. The mold and acrylic window were retained by stainless alloy plates. Direct shear was applied by a stepping motor that pulled one teflon plate outwards. Although the shear stress direction was opposite to the cell for shear deformation in semi-solid $\mathrm{Al}-\mathrm{Cu}$ alloys, both experiments apply direct shear to the sample. The teflon

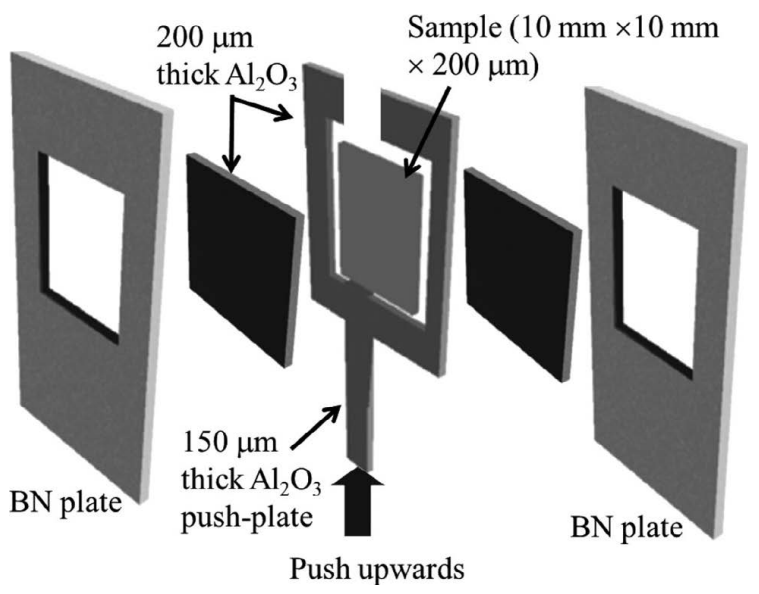

Fig. 1. Schematic of direct shear-cell for semi-solid Al-Cu alloy.

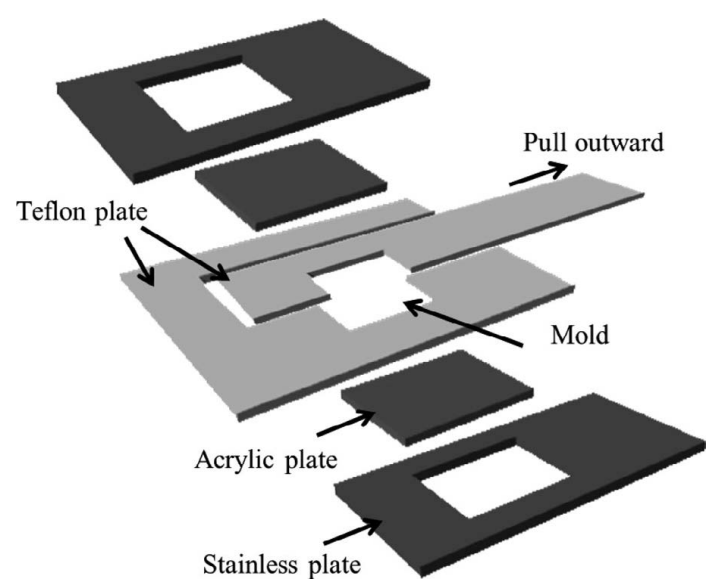

Fig. 2. Schematic of direct shear-cell for water-particle mixtures.

plate displacement rate was $50 \mu \mathrm{m} / \mathrm{s}$. The images were recorded by a high speed CMOS camera. The frame rate was $60 \mathrm{fps}$ and the pixel size was $33 \mu \mathrm{m} \times 33 \mu \mathrm{m}$.

\subsection{Quantitative Analysis for Solid Motion during Shear}

Past researches on the in-situ observation of deformation in semi-solid alloys showed that the deformation behaviors in semi-solid $\mathrm{Al}-\mathrm{Cu}$ alloys were fundamentally similar to semi-solid $\mathrm{Fe}-\mathrm{C}$ alloys. ${ }^{22-24)}$ Image sequences in semi-solid Al-Cu alloys were used in this study. ${ }^{23,24)}$ The solid particles were partially overlapped in the thickness direction because the sample thickness of $200 \mu \mathrm{m}$ is larger than the solid particle size of $96 \mu \mathrm{m}$. It was therefore difficult to trace each solid particle during shear and a two dimensional quantitative image analysis of solid motion was performed instead. The transmission image was divided into a domain with dimensions of $120 \times 120 \mu \mathrm{m}^{2}$, which is approximately 1.2 times larger than the mean solid particle size. The correlation pattern was examined between $\mathrm{I}_{\mathrm{sl}}(\mathrm{x}, \mathrm{y}, \mathrm{t})$ and $\mathrm{I}_{\mathrm{sl}}(\mathrm{x}+\Delta \mathrm{x}$, $y+\Delta y, t+\Delta t$ ), where $I_{s l}$ is the intensity of transmitted $X$-rays, in each domain and $\mathrm{t}$ is time. $\Delta \mathrm{x}, \Delta \mathrm{y}$ were calculated to be the point at which the following Eq. (2.1) becomes minimum.

$$
\begin{aligned}
\mathrm{S}(\Delta \mathrm{x}, \Delta \mathrm{y}) & =\int_{\mathrm{y}-\delta / 2}^{\mathrm{y}+\delta / 2} \int_{\mathrm{x}-\delta / 2}^{\mathrm{x}+\delta / 2}\left[\mathrm{I}_{\mathrm{sl}}(\mathrm{x}, \mathrm{y}, \mathrm{t})\right. \\
& \left.-\mathrm{I}_{\mathrm{sl}}(\mathrm{x}+\Delta \mathrm{x}, \mathrm{y}+\Delta \mathrm{y}, \mathrm{t}+\Delta \mathrm{t})\right]^{2} \mathrm{dxdy}
\end{aligned}
$$


The solid velocities in the $\mathrm{x}$ and $\mathrm{y}$ directions are given by

$$
\begin{aligned}
& u_{x}=\frac{\Delta x}{\Delta t} \\
& u_{y}=\frac{\Delta y}{\Delta t}
\end{aligned}
$$

The strain rate in the $\mathrm{x}$ direction, $\varepsilon_{11}$, the strain rate in the $\mathrm{y}$ direction, $\mathcal{E}_{22}$, and the shear strain rate, $\mathcal{E}_{12}$, where 1 and 2 indicate positive $\mathrm{x}$ and $\mathrm{y}$ directions, are given by

$$
\begin{gathered}
\varepsilon_{11}=\frac{\partial \mathrm{u}_{\mathrm{x}}}{\partial \mathrm{x}} \ldots \ldots \ldots . . . . \\
\varepsilon_{22}=\frac{\partial \mathrm{u}_{\mathrm{y}}}{\partial \mathrm{y}} \ldots \ldots \ldots . . \\
\varepsilon_{12}=\frac{1}{2}\left(\frac{\partial \mathrm{u}_{\mathrm{x}}}{\partial \mathrm{y}}+\frac{\partial \mathrm{u}_{\mathrm{y}}}{\partial \mathrm{x}}\right) . . .
\end{gathered}
$$

The divergence of solid velocity, $\operatorname{div}(\overrightarrow{\mathrm{u}})$, which corresponds to a change in solid fraction, is obtained by the following equation.

$$
\operatorname{div}(\overrightarrow{\mathrm{u}})=\frac{\partial \mathrm{u}_{\mathrm{x}}}{\partial \mathrm{x}}+\frac{\partial \mathrm{u}_{\mathrm{y}}}{\partial \mathrm{y}}
$$

Mass conservation gives the following relationship.

$$
\frac{\partial f_{s}}{\partial t}+\frac{\partial}{\partial x}\left(f_{s} u_{x}\right)+\frac{\partial}{\partial y}\left(f_{s} u_{y}\right)=0
$$

where, $f_{s}$ is the solid fraction.

Inserting Eq. (2.7) into Eq. (2.8), the following relationship is obtained.

$$
\frac{\partial \mathrm{f}_{\mathrm{s}}}{\partial \mathrm{t}}+\mathrm{f}_{\mathrm{s}} \operatorname{div}(\overrightarrow{\mathrm{u}})=0
$$

Here, the solid fraction is assumed to be uniform. Since the solid fraction is almost uniform at the initial stage, the assumption is roughly valid.

\subsection{Calculation of Initial Solid Fraction in Semi-solid Alloys}

\subsubsection{Semi-solid Al-Cu Alloys}

The 3D initial solid fraction, $g_{s}$, prior to shear was calculated from the intensity of the transmitted X-ray beam though regions of $100 \%$ liquid, $\mathrm{I}_{\mathrm{L}}, 100 \%$ solid, $\mathrm{I}_{\mathrm{S}}$, and semisolid, ISL. Further details are explained in Ref. 23). In a region, $\mathrm{D}$, the solid fraction is expressed by the following equation.

$$
\left[\mathrm{g}_{\mathrm{S}}\right]_{\mathrm{D}}=\frac{\ln \mathrm{I}_{\mathrm{SL}}-\ln \mathrm{I}_{\mathrm{L}}}{\ln \mathrm{I}_{\mathrm{S}}-\ln \mathrm{I}_{\mathrm{L}}}
$$

The 2D initial solid fraction was also calculated by image analysis. The solid particles were distinguished from the liquid by defining the outline of the solid particles. Then the $2 \mathrm{D}$ solid fraction was defined as the area ratio between the solid/liquid.

\subsubsection{Water-particle Mixtures}

The 3D initial solid fraction prior to shear was calculated by the volume ratio between the solid/liquid. Note that it was assumed that the shape of each solid particle was spher- ical and the diameter of all particles was $500 \mu \mathrm{m}$. The solid volume was calculated from the number of polystyrene particles in the mold. The liquid volume was $0.08 \mathrm{ml}$ from the measurement of the volume of the mold. The $2 \mathrm{D}$ initial solid fraction was also calculated by the area ratio between the solid/liquid.

\section{Results and Discussion}

\subsection{In-situ Observation of Shear Deformation in Semi- solid Al-Cu Alloys}

Figure 3 shows the radiography of semi-solid Al- $\mathrm{Cu}$ alloys prior to shear. ${ }^{23)}$ The calculated 3D and 2D solid fractions are $\sim 48 \%$ and $\sim 71 \%$ respectively. The mean solid particle size (d) was $96 \mu \mathrm{m}$. The shape factor, ${ }^{27)}$ which describes the roundness of solid particles, was examined by the following equation.

$$
\mathrm{F}=4 \pi \frac{\mathrm{A}}{\mathrm{U}^{2}}
$$

where, $A$ is area and $U$ is perimeter. In the case of spherical shape (circle in radiography), $\mathrm{F}$ is equal to 1 . The projectedarea shape factor of the solid particles is $\mathrm{F}=0.8$.

The increment of the $\mathrm{Al}_{2} \mathrm{O}_{3}$ push plate was normalized by the mean solid particle size, $\mathrm{d}$. The semi-solid microstructure after a $9.3 \mathrm{~d}$ increment of $\mathrm{Al}_{2} \mathrm{O}_{3}$ push plate motion is shown in Fig. 4(a). The solid motion was analyzed when direct shear was applied to the semi-solid microstructure shown in Fig. 4(a) during a $0.5 \mathrm{~d}$ increment of $\mathrm{Al}_{2} \mathrm{O}_{3}$ push plate displacement. Figure 4(b) shows the solid velocity vectors. The solid particles ahead of the $\mathrm{Al}_{2} \mathrm{O}_{3}$ push plate mainly translated upwards parallel to the shear plane and the magnitude of solid velocity vectors decreased with distance from the $\mathrm{Al}_{2} \mathrm{O}_{3}$ push plate front. The direction of solid velocity vectors gradually changed to the right toward the shear plane. The right component of solid velocity vectors was dominant at the right hand side of the shear plane. The impingement between solid particles and the rearrangement of solid particles frequently occurred during shear, ${ }^{22-24)}$ leading to momentum diffusion of solid particles to the right direction. In the case of incompressible Newtonian fluid,

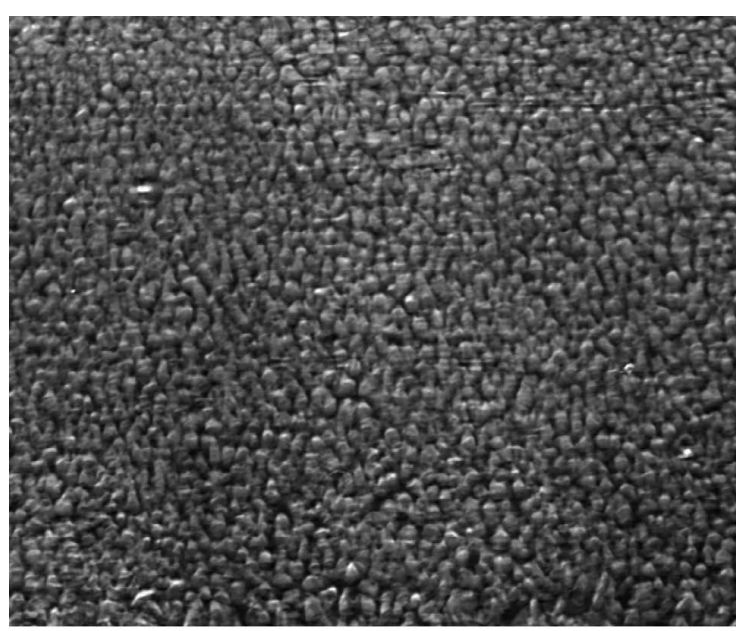

$500 \mu \mathrm{m}$

Fig. 3. Radiograph of semi-solid $\mathrm{Al}-15 \mathrm{Cu}$ alloy prior to shear. ${ }^{23)}$ 
such as the metallic melt and the water solution, the mass conservation law is always satisfied. Thus, the divergence of the flow velocity should be zero at any region. The gradual change of the solid velocity from the upward to the right indicates that the divergence is non-zero in the deformation region. Namely, the solid motion observed by the in-situ observation is a characteristic of a dense particulate (granular) flow. ${ }^{23,24)}$

Figure 4 (c) shows the distribution of shear strain rate, $\varepsilon_{12}$, calculated with Eq. (2.6). A negative value of shear strain rate is shaded blue. A relatively high shear strain rate is localized at the upper right region of the $\mathrm{Al}_{2} \mathrm{O}_{3}$ push plate which is equivalent to a shear band. The mean shear strain rate in the localized region was $-2 \times 10^{-2} \mathrm{~s}^{-1}$. The overall global shear rate is expressed by the following equation.

$$
\frac{1}{\mathrm{w}} \cdot \frac{\mathrm{du}}{\mathrm{dt}}
$$

where $\mathrm{w}$ is the width of the sample (in the $\mathrm{x}$-direction), $\mathrm{u}_{\mathrm{p}}$ is the push-plate displacement (in the y-direction) and $\mathrm{t}$ is time. The overall global shear rate was $3 \times 10^{-3} \mathrm{~s}^{-1}$, which was an order of magnitude lower than the localized shear strain rate.

The distribution of the divergence of solid velocity is shown in Fig. 4(d). Positive values of the divergence are shaded in red. The divergence is positive in the shear domain where the shear strain rate was relatively high as shown in Fig. 4(c). The mean divergence was $1 \times 10^{-2} \mathrm{~s}^{-1}$ at the shear domain. A positive value of the divergence indicates a decrease in the solid fraction, if the solid fraction is uniform. Namely, the solid fraction tended to decrease in the region of localized shear strain rate. On the other hand, negative values of the divergence (shaded blue) were mainly distributed at the $\mathrm{Al}_{2} \mathrm{O}_{3}$ push plate front, where the loading mode was highly compressive. The compressive force

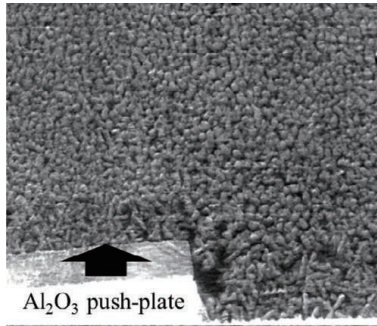

(a) Radiograph

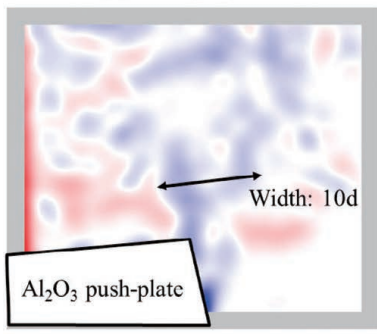

(c) Shear strain rate

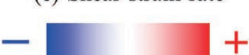

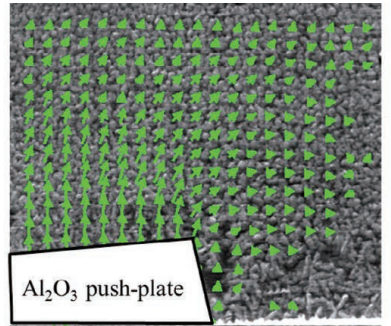

(b) solid velocity vector

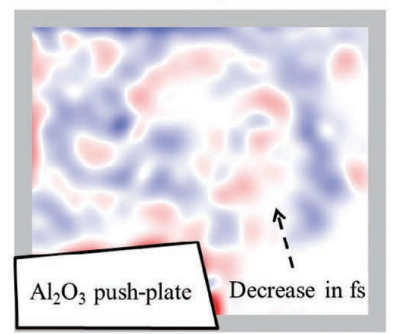

(d) Divergence of solid rate $\overline{200} \mu \mathrm{m}$ increase fs decrease
Fig. 4. (a) Radiograph of semi-solid $\mathrm{Al}-15 \mathrm{Cu}$ alloy before $0.5 \mathrm{~d}$ increment of push-plate motion. (b) Solid velocity vector, distribution of (c) shear strain rate and (d) divergence of solid velocity in a $0.5 \mathrm{~d}$ increment of the push-plate motion. The divergence corresponds to the change in solid fraction $\left(f_{s}\right)$. caused the increase in solid fraction (compaction).

Past research on the in-situ observation of shear deformation in semi-solid alloys ${ }^{22}$ proved that impingement between solid particles and rearrangement of solid particles resulted in shear induced dilation, corresponding to the decrease in solid fraction in the shear domain. Figure 5 shows the dynamics of solid motion in the shear domain in semi-solid $\mathrm{Fe}-\mathrm{C}$ alloys. The semi-solid microstructure before and after a $2 \mathrm{~d}$ increment of the push-plate motion are shown in Figs. 5(a) and 5(b), respectively. Large liquidfilled regions were created between the solid particles at the upper left region of the $\mathrm{Al}_{2} \mathrm{O}_{3}$ push plate. Figures 5(c)-5(f) show the image sequences in the white box in Figs. 5(a) and 5(b) for a $2 \mathrm{~d}$ increment of $\mathrm{Al}_{2} \mathrm{O}_{3}$ plate displacement. The sequence clearly shows that the liquid-filled spaces between the solid particles are enlarged during shear. The five solid particles, which are labeled A-E in Figs. 5(g)-5(j), are picked up to explain the dilation occurring during the deformation. As force is transmitted though impingement between solid particles, the $\mathrm{Al}_{2} \mathrm{O}_{3}$ push plate pushed particle $\mathrm{D}$ upwards into $\mathrm{E}$ and $\mathrm{C}$. The rotation and displacement of particle $\mathrm{C}$ led to push $\mathrm{A}$ to the left and $\mathrm{B}$ upwards, which opened up the space between A, B and C. The large liquidfilled space was created by the rearrangement of solid particles including translation and rotation. Similar dilation events were observed during the shear of semi-solid $\mathrm{Al}-\mathrm{Cu}$ alloys. $^{23)}$

The shear band was defined as the region of coupled localized shear strain and decreased solid fraction as shown in Figs. 4(c) and 4(d). The shear band width was approximately 10 mean particles diameter. Various experimental studies $^{9,10)}$ have been conducted on shear band width in semi-solid metallic alloys and compacted granular materials, such as dense-sand and glass beads. The shear bands are typically 7-18 mean particles diameter in semi-solid metallic alloys, which is similar to those that form in compacted granular materials (6-20 mean particles diameter). In-situ observation showed that the shear band width of 10 mean particles diameter in semi-solid $\mathrm{Al}-\mathrm{Cu}$ alloys is within the range of previous experimental data.

\subsection{In-situ Observation of Shear Deformation in Water-particle Mixtures}

Figure 6 shows a photograph of water-polystyrene particle mixtures. The projected-area shape factor, $\mathrm{F}$, is 1.0 . The calculated 3D and 2D solid fractions are $34 \%$ and $81 \%$, respectively. Note that the specimen is a monolayer of particles with diameter $500 \mu \mathrm{m}$ in a mold of $800 \mu \mathrm{m}$ thickness, leading to a remarkably lower 3D solid faction than that of 2D. Images of every $1 \mathrm{~d}$ increment of teflon plate motion are shown in Figs. 7(a)-7(c). The image sequences show that liquid-filled spaces gradually enlarge near the shear plane as shown by the red dotted circle, which is similar to the shear induced dilation in semi-solid metallic alloys as shown in Fig. 5. At the teflon plate front, the compression caused agglomeration of polystyrene particles, resulting in an increase in solid fraction.

The polystyrene particle motion during a 1d increment of teflon plate motion between Figs. 7(b) and 7(c) was analyzed by the procedure described in section 2.3. The distribution of solid velocity vectors is shown in Fig. 7(d). The 
(a)

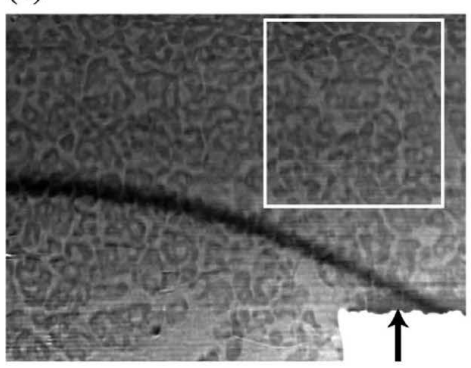

(c)

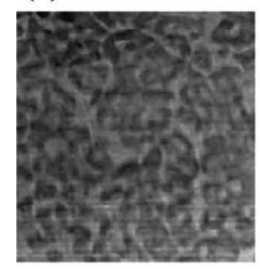

(g)

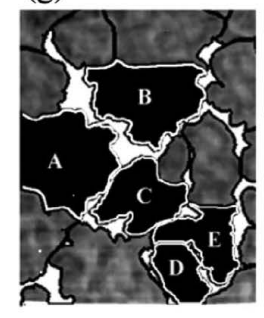

(d)

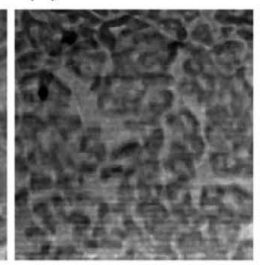

(h)

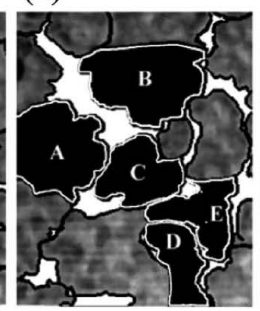

(b)

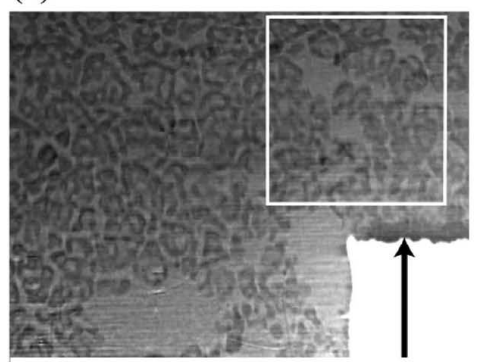

(e)

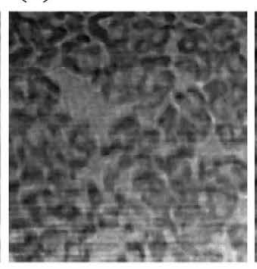

(f)

$50 \overline{\mu \mathrm{m}}$

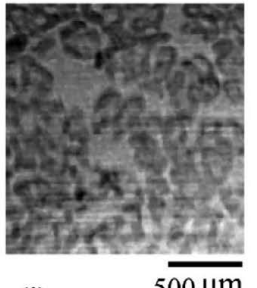

(i)

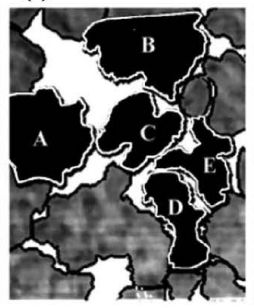

$5 \overline{500 \mu \mathrm{m}}$

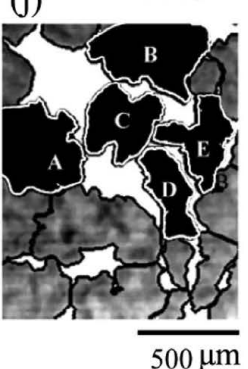

Fig. 5. Deformation of semi-solid $\mathrm{Fe}-2 \mathrm{C}$ alloy. ${ }^{22}$ The microstructure (a) before and (b) after a $2 \mathrm{~d}$ increment of the pushplate motion. (c)-(f) Four images from the white box in (a) and (b). (g)-(j) The five solid particles, labeled A-E, that play an important role in dilation. Liquid regions between solid particles are defined as white and solid particle boundaries are traced black.

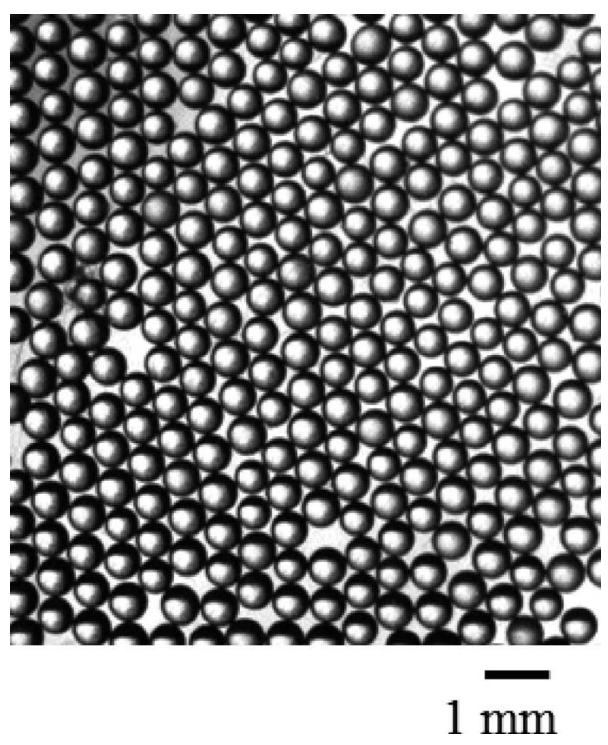

Fig. 6. Photograph of water-polystyrene particle mixtures.

polystyrene particles translated parallel to the shear plane at the teflon plate front and the downward component of solid velocity vector increased close to the shear plane. This increase in component perpendicular to the shear plane in the shear domain is a common feature with semi-solid Al$\mathrm{Cu}$ alloys. However, the solid velocity vectors in the semisolid Al-Cu alloys (Fig. 4(b)) are more widely distributed in the stationary half of the shear-cell compared to the water-polystyrene particle mixtures.

Figure 7(e) shows the distribution of shear strain rate. Positive values of shear rate are shaded in red. The high shear strain regions were mainly distributed in the shear plane. The mean shear strain rate in this localized region was $3 \times 10^{-2} \mathrm{~s}^{-1}$. The distribution of divergence of solid velocity is shown in Fig. 7(f). Positive values of the divergence of solid velocity, corresponding to a decrease in solid fraction and shaded red, were relatively high in the localized region of shear strain rate as shown in Fig. 7(e). The mean divergence of solid velocity was $5 \times 10^{-2} \mathrm{~s}^{-1}$ at the shear domain. Examination of Figs. 7(e)-7(f) showed that the shear band width was approximately 5 mean particles diameter.

\subsection{Influence of Solid Particle Shape on Shear Defor- mation}

Comparing the shear band width, for the 2 samples in Figs. 4 and 7, the shear band width of the semi-solid Al-Cu alloys is approximately two times wider than that of the water-particle mixtures. This is mainly attributed to the difference in the shape of solid particles. The polystyrene particles have higher shape factor $(\sim 1)$ and a narrower particle size distribution than those of solid particles in semi-solid $\mathrm{Al}-\mathrm{Cu}$ alloys. Shear deformation causes solid-solid interactions including impingement between solid particles and rearrangement of solid particles, especially in the shear domain. A combination of rotation and translation of indi- 

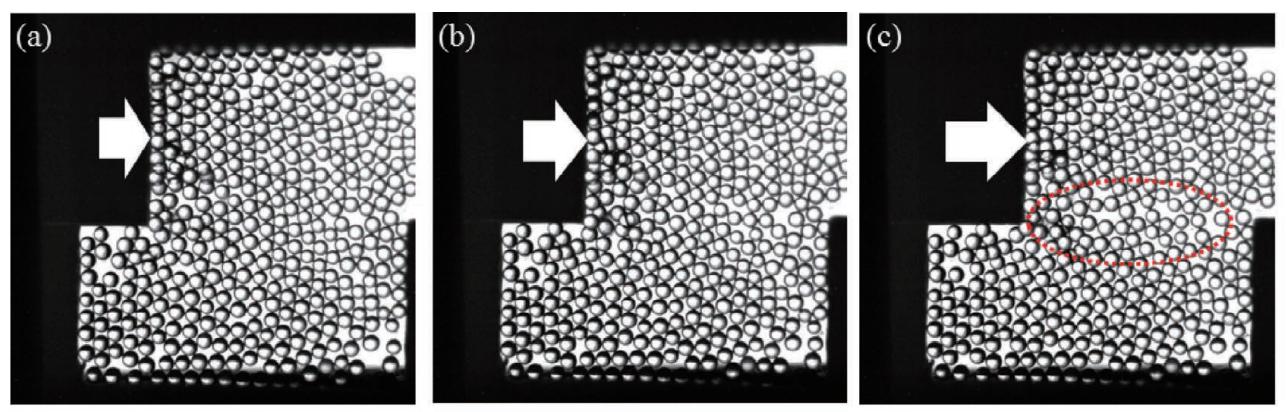

(a-c) Deformation during a $2 \mathrm{~d}$ increment of teflon plate.

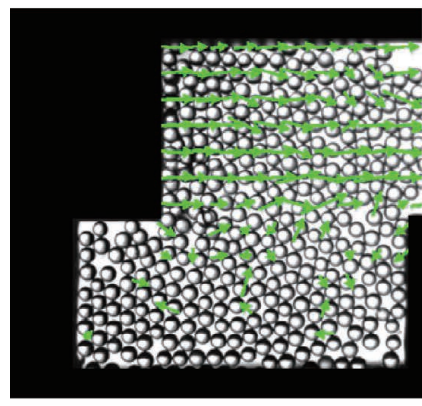

(d) Solid velocity vector

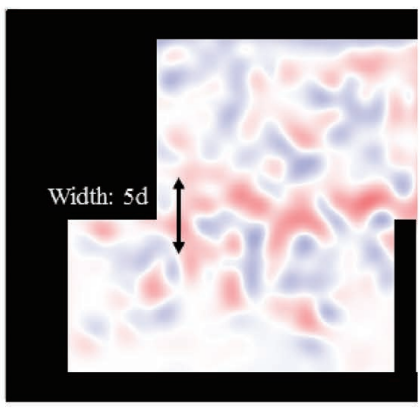

(e) Shear strain rate

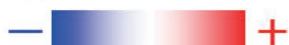

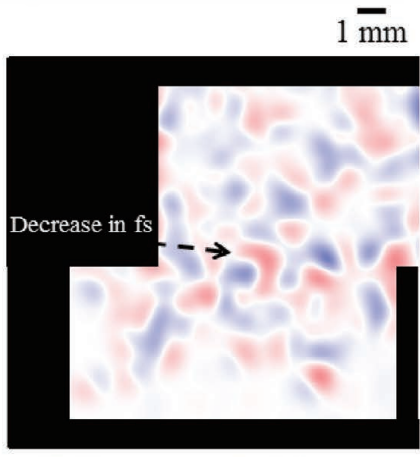

(f) Divergence of solid rate

increase fs decrease

Fig. 7. (a)-(c) Deformation of water-particle mixtures every $1 \mathrm{~d}$ displacement of teflon plate. The red dotted circle shows the region where the solid faction decreased. (d) Solid velocity vector, distribution of (e) shear strain rate and (f) divergence of solid velocity in a $1 \mathrm{~d}$ displacement of teflon plate between (b) and (c). The divergence corresponds to the change in solid fraction $\left(\mathrm{f}_{\mathrm{s}}\right)$.

vidual solid particles occurs during rearrangement. In the case of spherical polystyrene particles, a relatively small force acts on the particle surroundings as they rotate. Actually, most of the particles in the lower side of the shear plane showed no movement as shown in Fig. 7(d). The shear strain rate was therefore localized in a narrow region (Fig. 7(e)). On the other hand, more irregularly shaped solid particles cause a significant force to act on the surrounding particles and force is transmitted over a longer distance as they rotate. Because of this, the solid velocity vectors were distributed in the range of 16 particles from the right side of $\mathrm{Al}_{2} \mathrm{O}_{3}$ push plate as shown in Fig. 4(b), and the localized region of shear strain rate becomes wider than that in the spherical particles (Fig. 4(c)).

The solid particle shape also influenced the liquid-filled spaces between solid particles which are created by rearrangement. Spherical particles basically do not create interstitial space as they rotate. In contrast, irregularly shaped solid particles with a shape factor far from 1 create significant interstitial space as they rotate, resulting in a remarkable decrease in solid fraction (e.g. Figs. 5(g)-5(j)). The differences in detailed behavior between the semi-solid alloys and water-polystyrene mixtures in Figs. 4 and 7 are also likely to have been affected by differences in the initial packing density of the particles and the number of particles in the shear-cell.

The discussion on the influence of solid particle shape indicates that the shear band width is narrow, and the decrease in solid fraction in the shear band is remarkably small in the case of semi-solid metal alloys with spherical solid particles. It is therefore expected that segregation in castings caused by the deformation in semi-solid metal alloys is reduced by the control of solid particle shape.

\section{Conclusion}

Synchrotron X-ray imaging has been used to directly image deformation in semi-solid $\mathrm{Al}-\mathrm{Cu}$ alloys. The solid motion was quantitatively analyzed to characterize the deformed microstructures. For comparison, in-situ observation of shear deformation in water-particle mixtures was carried out to study the influence of solid particle shape on shear deformation.

(1) Many of the grain level phenomena were common to deformation of semi-solid alloys and water-polystyrene particle mixtures. In both cases, solid particles rearranged by translation and rotation which caused strain localization in regions of decreased solid fraction.

(2) The distribution of solid velocity in semi-solid Al$\mathrm{Cu}$ alloys was similar to the water-particle mixtures. The solid particles translated in the direction of push-plate motion at the push plate front. The perpendicular component of solid velocity to the shear plane increased due to impingement and rearrangement of solid particles in the shear domain. However, the solid velocity vectors of solid particles in semi-solid Al-Cu alloys were more widely distributed compared to those observed in water-particle mixtures.

(3) A high shear strain rate was localized near the shear plane where impingement and particle rearrangement frequently occurred both for semi-solid $\mathrm{Al}-\mathrm{Cu}$ alloys and water-particle mixtures. The divergence of solid velocity showed a decrease in solid fraction at the localized region of the shear strain rate.

(4) The shear band width, where the high shear strain rate and decreased solid fraction localized, was $\sim 10$ mean particles diameter for semi-solid Al-Cu alloys and $\sim 5$ mean 
particles diameter for water-particle mixtures. The irregularly shaped solid particles caused the wider shear band width in semi-solid $\mathrm{Al}-\mathrm{Cu}$ alloys.

\section{Acknowledgements}

Synchrotron experiments were performed at the 20B2 of SPring-8 under Proposal No. 2009A(B)0014, 2010A1420, 2011A1209. 2011B1096, 2012A1110, 2012B1173 with the approval of the Japan Synchrotron Radiation Research Institute (JASRI). The in-situ observation technique was developed with the support of "ISIJ Innovative Program for Advanced Technology", ISIJ Research Promotion Grant. Analysis was carried out under JSPS KAKENHI Grant number 24560910, 24246124, 24226018. This collaboration is also supported by a Royal Society Daiwa Anglo-Japanese Foundation International Exchanges Award.

\section{REFERENCES}

1) J. A. Dantzig and M. Rappaz: Solidification, EPFL Press, Switzerland, (2009), 567.

2) S. A. Metz and M. C. Flemings: AFS Trans., 78 (1970), 453.

3) M. C. Flemings: Metall. Trans., 22A (1991), 957.

4) C. P. Chen and C.-Y. A. Tsao: Acta Mater., 45 (1997), 1955.

5) E. Tzimas and A. Zavaliangos: Acta Mater., 47 (1999), 517.

6) E. Tzimas and A. Zavaliangos: Mater. Sci. Eng. A, 289 (2000), 228.

7) T. Sumitomo, D. H. StJohn and T. Steinberg: Mater. Sci. Eng. A, 289 (2000), 18.

8) M. Kikuchi and R. Kopp: Ann. CIRP, 51 (2002), 653.

9) C. M. Gourlay and A. K. Dahle: Nature, 445 (2007), 70

10) C. M. Gourlay, B. Meylan and A. K. Dahle: Acta Mater., 56 (2008), 3403 .
11) I. Kang and I. Ohnaka: J. JFS, 69 (1997), 119.

12) R. H. Mathiesen, L. Arnberg, F. Mo, T. Weitkamp and A. Snigirev: Phys. Rev. Lett., 83 (1999), 5062.

13) H. Yasuda, I. Ohnaka, K. Kawasaki, A. Sugiyama, T. Ohmichi, J. Iwane and K. Umetani: J. Cryst. Growth, 262 (2004), 645.

14) N. Mangelinck-Noel, H. Nguyen-Thi, G. Reinhart, T. Schenk, V. Cristiglio, M. D. Dupouy, J. Gastaldi, B. Billia and J. Hartwig: $J$. Phys. D, 38 (2005), A28.

15) B. Li, H. D. Brody, D. R. Black, H. E. Burdette and C. Rau: J. Phys. D, 39 (2006), 4450.

16) S. Terzi, L. Salvo, M. Suery, N. Limodin, J. Adrien, E. Maire, Y. Pannier, M. Bornert, D. Bernard, M, Felberbaum, M. Rappz and E. Boller: Scr. Mater., 61 (2009), 449.

17) H. Yasuda, Y. Yamamoto, N. Nakatsuka, T. Nagira, M. Yoshiya, A. Sugiyama, I. Ohnaka, K. Umetani and K. Uesugi: Int. J. Cast Met. Res., 22 (2008), 125.

18) H. Yasuda, Y. Yamamoto, N. Nakatsuka, M. Yoshiya, T. Nagira, A. Sugiyama, I. Ohnaka, K. Uesugi and K. Umetani: Int. J. Cast Met. Res., 22 (2009), 15.

19) H. Yasuda, T. Nagira, A. Sugiyama, M. Yoshiya, N. Nakatuska, K. Uesugi, K. Umetani: Bull. Iron. Steel. Inst. Jpn., 15 (2010), 9.

20) H. Yasuda, T. Nagira, M. Yoshiya, N. Nakatsuka, A. Sugiyama, K. Uesugi and K. Umetani: ISIJ Int., 51 (2011), 402.

21) H. Yasuda, T. Nagira, M. Yoshiya, M. Uesugi, N. Nakatsuka, M. Kiire, A. Sugiyama, K. Uesugi and K. Umetani: IOP Conf. Ser. Mater. Sc. Eng., 27 (2011), 012084.

22) T. Nagira, C. M. Gourlay, A. Sugiyama, M. Uesugi, Y. Kanazawa, M. Yoshiya, K. Uesugi, K. Umetani and H. Yasuda: Scr. Mater., 64 (2011), 1129.

23) C. M. Gourlay, A. K. Dahle, T. Nagira, N. Nakatsuka, K. Nogita, K. Uesugi and H. Yasuda: Acta Mater., 59 (2011), 4933.

24) C. M. Gourlay, T. Nagira, A. K. Dahle, N. Nakatsuka, K. Uesugi and H. Yasuda: IOP Conf. Ser.: Mater. Sci. Eng., 27 (2011), 012086.

25) A. Sugiyama and I. Ohnaka: Tetsu-to-Hagané, 81 (1995), 46.

26) K. Umetani, K. Uesugi, M. Kobatake, A. Yamamoto, T. Yamashita and S. Imai: Nucl. Instr. Meth. A, 609 (2009), 38.

27) W. Püttgen, W. Bleck, G. Hirt and H. Shimahara: Adv. Eng. Mater., 9 (2007), 231. 